\title{
Responsabilidad de los padres, secreto profesional y confidencialidad médica. ¿Cómo se conjugan para asegurar la salud de los adolescentes
}

\author{
Parent's responsibility, professional secrecy and medical \\ confidentiality. How do they combine to ensure adolescents \\ health?
}

AÍDA KEMELMAJER DE CARLUCCI*

Resumen: El artículo analiza detenidamente la definición y contenido de secreto profesional y el derecho a la intimidad, para luego presentarnos sus implicancias en el orden público y el privado. A partir de ello, nos presenta los principales argumentos a favor y en contra de que los adolescentes tengan derecho al secreto profesional frente a sus representantes. Finalmente, el artículo nos presenta la jurisprudencia existente sobre la materia, lo establecido en la Declaración Ottawa y los casos específicos del ejercicio del secreto profesional en los supuestos de interrupción del embarazo y diagnóstico de VIH.

Palabras clave: secreto profesional - confidencialidad - adolescentes responsabilidad de los padres

Summary: The article carefully analyzes the definition and content of professional secrecy and the right to privacy and introduces their implications on public and private policy. On that basis, main arguments in favor and against adolescents entitle to exercise the right to professional secrecy towards their representatives are presented. Finally, this article presents the existing case-law on that subject, provisions according the Ottawa Declaration and specific cases concerning professional secrecy exercise in the assumptions on termination pregnancy and HIV diagnosis.

Keywords: professional secrecy - confidentiality - adolescents - parents responsibility

CONTENIDO: I. IMPORTANCIA DEL TEMA Y LÍMITE DE ESTAS REFLEXIONES.II. ETIMOLOGÍA.- III. SECRETO PROFESIONAL. CONCEPTO.- IV. EL SECRETOY LOSDERECHOSFUNDAMENTALESIMPLICADOS. ELDERECHOALAINTIMIDAD.V. EL INTERÉS PÚBLICOY PRIVADO COMPROMETIDO EN EL TEMA DEL SECRETO PROFESIONAL DEL MÉDICO.- VI. HISTORIA DEL SECRETO PROFESIONAL MÉDICO.- VII. ASPECTOS QUE COMPRENDE EL SECRETO MÉDICO.-

* Integrante del Comité Nacional de Ética en la Ciencia y la Tecnología de la República Argentina. Ex jueza de la Suprema Corte de Justicia de la Provincia de Mendoza. Profesora invitada en numerosas universidades argentinas y extranjeras. 
VIII. NORMATIVA GENERAL.- IX. SUJETO OBLIGADO.-X. SUJETO BENEFICIADO.XI. SANCIÓN POR EL INCUMPLIMIENTO DE ESTAS OBLIGACIONES.- XII. EL SECRETO MÉDICO Y LOS NIÑOS, NIÑAS Y ADOLESCENTES.- XIII. PRIMER PUNTO DE PARTIDA: PRESENCIA DE UN MENOR COMPETENTE, AUTÓNOMO.XIV. SEGUNDO PUNTO DE PARTIDA. EL INTERÉS SUPERIOR DEL NIÑO.XV. TERCER PUNTO DE PARTIDA. EL DERECHO DEL NIÑO MADURO FRENTE A SUS REPRESENTANTES.- XVI. EL DERECHO AL SECRETO DEL ADOLESCENTE. DOS POSICIONES ENCONTRADAS.- XVII. FUNDAMENTOS DE LA TESIS NEGATIVA, O SEA, LA QUE SOSTIENE QUE LA PERSONA MENOR DE EDAD, AUN MADURA O COMPETENTE, NO TIENE DERECHO AL SECRETO PROFESIONAL FRENTE A SUS REPRESENTANTES LEGALES.- XVIII. FUNDAMENTOS DE LA TESIS POSITIVA, O SEA, LA QUE SOSTIENE QUE LA PERSONA MENOR DE EDAD MADURA O COMPETENTE TIENE DERECHO AL SECRETO PROFESIONAL TAMBIÉN EN CONTRA DE SUS REPRESENTANTES.- XIX. LA TESIS POSITIVA EN LA DECLARACIÓN DE OTTAWA.- XX. UN PROBLEMA ESPECÍFICO: LA POSICIÓN POSITIVA Y EL PROBLEMA DEL PAGO DE LOS HONORARIOS MÉDICOS.XXI.JURISPRUDENCIA QUE APOYA LA TESIS AFIRMATIVA.-XXII. CONSECUENCIAS DE LA TESIS AFIRMATIVA: EL MÉDICO, INTERMEDIARIO ENTRE EL NIÑO Y LA FAMILIA.- XXIII. EXCEPCIONES A LA OBLIGACIÓN DE GUARDAR EL SECRETO.XXIV. UN CASO PARTICULAR: LA INTERRUPCIÓN DEL EMBARAZO SIN COMUNICACIÓN A LOS PADRES EN LOS PAÍSES EN LOS QUE LA PRÁCTICA ES LÍCITA. EL SECRETO MÉDICO FRENTE AL PEDIDO DE LA ADOLESCENTE QUE LA INTERVENCIÓN NOSECOMUNIQUEA LOS PADRES.-XXV.OTROCASOESPECÍFICO. LOS TEST PARA DETECTAR VIH.- XXVI. CONCLUSIONES PROVISORIAS.

A menudo, los hijos se nos parecen, y así nos dan la primera satisfacción... Cargan con nuestros dioses y nuestro idioma, con nuestros rencores y nuestro porvenir, por eso nos parece que son de goma... Nos empeñamos en dirigir sus vidas sin saber el oficio y sin vocación. Les vamos transmitiendo nuestras frustraciones con la leche templada y en cada canción

JOAN MANUEL SERRAT, Esos locos bajitos

I. IMPORTANCIA DELTEMA Y LÍMITE DE ESTAS REFLEXIONES El secreto ha sido objeto de reflexiones en la cultura académica y popular, por lo que una gran cantidad de dichos y manifestaciones atribuidas a famosos personajes reflexionan sobre su valor. Así, por ejemplo, se atribuye a Sócrates la frase «es más difícil guardar un secreto que tener un carbón ardiente en la lengua»; a Séneca, «si quieres que tu secreto sea guardado, guárdalo tu mismo»; al poeta Gibran Kahlil Gibran, «si revelas tus secretos al viento, no culpes al viento por revelarlos a los hombres»; a La Rochefoucauld, «cómo pretendemos que otro guarde nuestro secreto si nosotros no hemos podido guardarlo»; a Richelieu, el consejo «no decir sino lo que es necesario, a quien es necesario y cuando es necesario»; a Benjamín Franklin, «las tres cosas más difíciles de esta 
vida son: guardar un secreto, perdonar un agravio y aprovechar el tiempo». Son dichos populares españoles «en boca cerrada no entran moscas»; «en la boca del discreto, lo público es secreto»; en Japón se dice que «ni cien caballos al galope atraparán una frase imprudente» y que «si el pájaro no hubiese cantado, no le habrían disparado»; un proverbio francés dice: «se puede tener razones para hablar, pero no se necesita ninguna para callar»; uno árabe afirma «antes de hablar gira siete veces tu lengua en la boca»; en el Talmud se lee: «tu amigo tiene un amigo y el amigo de tu amigo tiene otro amigo; por consiguiente, sé discreto».

Pareciera, pues, que no es necesario argumentar demasiado en torno a la importancia que la gente de todas las épocas y países atribuye al silencio como sinónimo de confidencialidad, cualquiera sea el sector sociocultural al que pertenece.

Como es sabido, en el cuerpo humano se concentran la vida, la integridad física, la salud, la sensibilidad, el sufrimiento físico. En ese cuerpo también se ubican las decisiones relativas al modo de vida y al compromiso hacia el futuro (matrimonio, trabajo o servicios a cumplir), la procreación (su aceptación o rechazo), etcétera. No cabe dudar, entonces, cuánto vale el secreto que versa sobre ese cuerpo. Dicho de otro modo, el secreto sobre lo que pasa en el cuerpo es una cuestión central.

Diversas profesiones tienen vínculos con el cuerpo de las personas, pero las relativas a la medicina los presuponen en todos los casos.

Por eso, no debe extrañar que el secreto médico constituya uno de los principios fundamentales de la ética médica y que esté reconocido por todos o la mayoría de los códigos deontológicos de esa profesión. Efectivamente, en 1950, durante un gran debate realizado en la Academia de Ciencias Morales y Políticas de París sobre la moral médica, Portes pronunció una fórmula que luego pasó a ser repetida casi inconscientemente: «No hay medicina sin confianza, ni confianza sin confidencialidad, ni confidencialidad sin secreto» ${ }^{1}$. Confianza y confidencia son dos términos de sonido parecido, inseparables en la buena práctica de la medicina. Tiene confianza quien supone que se hace o se va a hacer algo que es necesario para su tranquilidad. Hace una confidencia quien comunica algo a alguien reservadamente, en secreto.

Los juristas de la mayoría de los países coinciden en que la materia del secreto médico es difícil, especialmente cuando se enfrenta al deber de denunciar a las autoridades. El maestro Sebastián Soler decía que «la revelación del secreto profesional es uno de los temas que mayores contradicciones en la interpretación ha provocado al interrogarse cuándo existe violación punible del secreto y cuándo

1 Reproducido por HOERNI, Bernard \& Michel BÉNÉZECH. Le secret médical. Confidentialité et discrétion en médecine. París: Masson, 1996, p. 12.

RESPONSABILIDAD

DE LOS PADRES,

SECRETO

PROFESIONAL Y

CONFIDENCIALIDAD

MÉDICA. ¿CÓMO

SE CONJUGAN

PARA ASEGURAR

LA SALUD DE LOS

ADOLESCENTES

PARENT'S

RESPONSIBILITY,

PROFESSIONAL

SECRECY AND

MEDICAL

CONFIDENTIALITY.

HOW DO THEY

COMBINE

TO ENSURE

ADOLESCENTS

HEALTH? 
el deber de denunciar $»^{2}$. En consonancia, otros autores reconocen que no existe una regla precisa y desprovista de ambigüedad que permita trazar con certeza la frontera entre la obligación del médico de no revelar las confidencias requeridas bajo secreto médico y la obligación de revelarlas cuando el valor protegido por el secreto, es decir, el derecho a la vida privada, entra en conflicto con otro valor fundamental ${ }^{3}$.

Por su parte, los médicos sostienen que las cuestiones vinculadas al secreto se encuentran entre los grandes inconvenientes que afrontan en la práctica profesional, especialmente, cuando tienen información que implica a miembros de la familia del paciente 4 . Por lo demás, en una sociedad que se vanagloria de privilegiar la información y la transparencia, la resistencia del secreto profesional, como la de todo secreto, se encuentra con grandes dificultades ${ }^{5}$. Por todo esto, y por otras razones, Delmas Marty ha podido decir que «más que una teoría jurídica, el secreto profesional aparece más bien como una búsqueda de un equilibrio jamás alcanzado» ${ }^{6}$.

No extraña, pues, que sobre el secreto sanitario y su protección hayan corrido ríos de tinta, y seguirán corriendo, a causa de la extensión y gravedad de los problemas que plantea a muchas personas, en trances trágicos o dramáticos ${ }^{7}$. En consecuencia, estas líneas no pretenden ser un análisis completo de la problemática. Me limitaré, en lo posible, una vez planteado el problema en general, a reflexionar sobre la cuestión cuando los adolescentes están implicados.

\section{ETIMOLOGÍA}

La raíz «secr» se encuentra en el vocablo latino scemere, que significa separar, aislar. El participio de scernere es secretus, origen del término secreto. O sea, lo secreto se distingue porque se lo separa de otras cosas.

El diccionario de la Real Academia de la lengua española define el secreto como aquella cosa que «se tiene reservada u oculta cuidadosamente».

2 SOLER, Sebastián. Derecho penal argentino. Buenos Aires: Tea, 1978, tomo IV, p. 117.

3 JAKHIAN, Edouard. "La Cour Européenne des Droits de l'Homme et le secret médical ou l'impossible équilibre». En Mélanges en hommage à Louis Edmond Pettiti. Bruselas: Bruylant, 1998, p. 467. El autor comenta los casos llegados al Tribunal Europeo de Derechos Humanos (TEDH) hasta 1998: $Z$ c/Finlandia, del 25 de febrero de 1997 (que relato más adelante, brevemente, en el texto); Mitterand c/Francia (herederos enfrentados a un médico que publica un libro, titulado, irónicamente, Le grand secret); $M c$ / Suecia (necesidad de revelar el secreto en un juicio en el que el médico es demandado por el paciente). El 9 de junio de 2011, el Centro Francés de Derecho Comparado organizó un coloquio titulado La dénonciation: droit ou devoir. Los trabajos fueron publicados bajo ese mismo título por la Société de Législation Comparée en el mismo año.

4 GILBAR, Roy. "Medical Confidentiality within the Family: the Doctor's Duty Reconsidered». International Journal of Law, Policy and the Family, XVIII, 1 (2004), p. 195.

5 MAGENDIE, Jean Claude. «Pouvoir, dans la transparence, prétendre à une part irréductible de secret». En HIRSCH, Emmanuel \& otros (dirs.). Éthique, justice et médecine. París: Université de Paris Sud 11, 2005, p. 16.

6 DeLmaS-MARTY, Mireille. «A propos du secret professionnel». Recueil Dalloz Sirey, XXXIX (1982).

7 Rodríguez Ramos, Luis. Prólogo. En Requejo Naveros, María Teresa. El delito de revelación de secreto médico y la protección penal de la información genética. Madrid: Colex, 2006. 
Por lo tanto, desde lo gramatical, se entiende por secreto todo aquello que se tiene reservado, oculto, aislado de la normal comunicación con los demás 8 . Se trata, pues, de un conocimiento que se aísla, poniendo obstáculos para que determinadas informaciones lleguen a ser conocidas por otras personas.

\section{SECRETO PROFESIONAL.CONCEPTO}

Se define al secreto profesional como el sigilo o reserva que corresponde a quien ejerce una profesión respecto del conocimiento que posee sobre otra persona cuando ese conocimiento ha sido obtenido por razón del desarrollo de la actividad profesional y la información ha sido necesaria para realizar la prestación o servicio a su cargo.

\section{EL SECRETO Y LOS DERECHOS FUNDAMENTALES IMPLICADOS. EL DERECHO A LA INTIMIDAD}

Algunas constituciones de los países latinoamericanos contienen referencias expresas al secreto; por ejemplo, el artículo 2.18 de la Constitución del Perú de 1993 dispone: «Toda persona tiene derecho a mantener reserva sobre sus convicciones políticas, filosóficas, religiosas o de cualquier otra índole, así como a guardar el secreto profesional».

Distintos valores jurídicos se relacionan con el secreto según sea la profesión ejercida. Por ejemplo, el secreto de la fuente de información del periodista se vincula a la libertad de expresión. En este sentido, el artículo 43 de la Constitución menciona expresamente este secreto cuando al regular el habeas data dice:

Toda persona podrá interponer esta acción para tomar conocimiento de los datos a ella referidos y de su finalidad, que consten en registros o bancos de datos públicos, o los privados destinados a proveer informes, y en caso de falsedad o discriminación, para exigir la supresión, rectificación, confidencialidad o actualización de aquellos. No podrá afectarse el secreto de las fuentes de información periodística.

El secreto profesional del abogado se une al derecho de defensa, y hace a la esencia, seguridad y garantía de un proceso. Revelarlo puede traer gran perturbación a las prácticas judiciales y dar lugar a «incalificables abusos que pondrían en peligro a la propia administración de justicia, generando escándalos y prohijando exacciones» ${ }^{9}$.

8 Verdú PAscuAL, Fernando. Secreto profesional médico. Normas y usos. Granada: Comares, 2005, p. 7.

9 CEPEDE, Analía de los Ángeles. El secreto profesional médico en materia de aborto. Documento Judicial 2010-543.

RESPONSABILIDAD

DE LOS PADRES,

SECRETO

PROFESIONAL Y

CONFIDENCIALIDAD

MÉDICA. ¿CÓMO

SE CONJUGAN

PARA ASEGURAR

LA SALUD DE LOS

ADOLESCENTES

PARENT'S

RESPONSIBILITY,

PROFESSIONAL

SECRECY AND

MEDICAL

CONFIDENTIALITY.

HOW DO THEY

COMBINE

TO ENSURE

ADOLESCENTS

HEALTH? 
Lo cierto es que, cualquiera sea la profesión, el derecho al secreto se vincula esencialmente a la intimidad y esta atadura muestra, desde el principio, la complejidad del problema ${ }^{10}$. En efecto, «el secreto evoca el silencio, lo íntimo, la discreción; por lo tanto, nada hay de inquietante para favorecer el respeto a la esfera privada. Pero el secreto, como opuesto a transparencia, es portador de oscuridad, tinieblas, disimulación, opacidad, clandestinidad, deslealtad $»^{11}$. Por ser la intimidad el valor fundamentalmente amparado, un requisito indispensable para que surja el deber jurídico de proteger el secreto es que la persona a la que atañe tenga voluntad de guardarlo como tal $^{12}$.

Algunas figuras jurídicas parten, precisamente, de un secreto que protege la salud, por ejemplo, el parto anónimo que garantiza a la madre el derecho a parir de modo seguro en un hospital, pero se enfrenta con el derecho fundamental de otra persona como es, el derecho de identidad del nacido ${ }^{13}$.

Sea como fuese, lo cierto es que el Tribunal Europeo de Derechos Humanos ha reconocido expresamente que los datos médicos relativos a la salud integran el derecho a la intimidad de la persona. Así lo dijo, entre otros, en el caso $Z$ c. Finlandia del 25 de febrero de 1997, en el que abordó la queja de una mujer que denunció que sus datos, entre los que contaban que ella era portadora del VIH, habían sido incorporados a un proceso en el que se discutía si su marido, que había violado a varias personas, debía ser condenado también por el delito de homicidio en razón de que a la época de los ilícitos, él conocía que también él estaba infectado. En el caso, los médicos que atendían a la mujer (clínicos y psiquiatra) habían invocado el secreto, pero el tribunal los obligó a revelarlos; más aun, el expediente médico se incorporó a la causa, y se decidió que la confidencialidad sobre estos datos durara solo diez años a partir de la sentencia. Independientemente del resultado final ${ }^{14}$, en el parágrafo 95 de la decisión del TEDH se lee:

10 Panizo Orallo, Santiago. "Riesgos del deber del secreto profesional para la eficacia del derecho». En SÁNCHEZ DE LA TORRE, Ángel \& otros (ed.). Eficacia del derecho. Teoría y aplicaciones. Madrid: Dykinson, 2010, p. 229.

11 MAGENDIE, Jean Claude. Pouvoir, dans la transparence, prétendre à une part irréductible de secret. En HIRSCH, Emmanuel \& otros (dirs.). Ob. cit., p. 15.

12 CoRCOY BIDASOLO, Mirentxu. «El tratamiento del secreto y el derecho a la intimidad del menor. Eficacia del consentimiento». En Protección de menores en el código penal. Madrid: Escuela Judicial, Consejo General del Poder Judicial, 1998, p. 311.

$13 \mathrm{Me}$ he referido a este tema en mi artículo «El derecho humano a conocer el origen biológico y el derecho a establecer vínculos de filiación. A propósito de la decisión del Tribunal Europeo de Derechos Humanos del 13/2/2003, en el caso "Odiévre c/ France"». En El derecho de familia ante el siglo XXI: aspectos internacionales. Madrid: Colex, 2004, p. 511 y en Derecho de Familia, 26 (2004), p. 77.

14 La queja principal fue rechazada, en definitiva, sobre la base del principio de proporcionalidad y la teoría del margen de discrecionalidad del Estado; en cambio, se estimó contrario al artículo 8 el plazo de confidencialidad de diez años, fijado de oficio por el tribunal. 
[...] la Corte tiene en cuenta el rol fundamental que la protección de los datos de carácter personal (entre los cuales se encuentran las informaciones relativas a la salud) juega en el ejercicio del respeto a la vida privada y familiar garantizado por el art. 8 de la Convención. El respeto del carácter confidencial de las informaciones sobre la salud constituye un principio esencial del sistema jurídico de todos los Estados contratantes de la Convención. Es capital no sólo para proteger la vida privada de los enfermos sino también para preservar la confianza en el cuerpo médico y los servicios de salud en general. Si esa protección faltase, las personas que necesitan cuidados médicos creerían que esa información de carácter íntimo, que es necesaria para su tratamiento, podría ser apropiada y consultada por otro, por lo que deciden ocultarla, lo que pone en peligro, en el caso de las enfermedades contagiosas, a la propia colectividad (Ver la Recomendación n ${ }^{\circ} \mathrm{R}$ (89) 14 sobre Las incidencias éticas de la infección VIH en el marco sanitario y social, aprobaba por el Comité de Ministros del Consejo de Europa el 24 octubre de 1989 y, especialmente, las observaciones generales sobre la confidencialidad de los datos médicos que figuran en el parágrafo 165 de la exposición de motivos). Por lo tanto, la legislación interna debe proveer garantías apropiadas para impedir toda comunicación o divulgación de datos de carácter personal relativos a la salud que no respeten las garantías previstas en el art. 8 de la Convención.

\section{EL INTERÉS PÚBLICO Y PRIVADO COMPROMETIDO EN EL TEMA DEL SECRETO PROFESIONAL DEL MÉDICO}

Jurídicamente se discute si el deber de secreto está basado solo en el acuerdo entre cliente y profesional, o si también responde al interés público. La tendencia mayoritaria, en la que se incluye el leading case del TEDH, Z c. Finlandia, del 25 de febrero de 1997, antes mencionado, se inclina por la segunda opción. Es decir, acepta que la obligación de no relevar los secretos a los que se ha accedido en el ejercicio de una profesión u oficio deriva de normas impuestas por el Estado para proteger el orden social ${ }^{15}$. Esta posición se funda en los siguientes argumentos:

a. el individuo que reclama el secreto se encuentra en la necesidad de acudir a quien ejerce una profesión para solucionar un problema que por sí solo no puede resolver, él renuncia a su intimidad no por capricho, sino por necesidad;

RESPONSABILIDAD

DE LOS PADRES,

SECRETO

PROFESIONAL Y

CONFIDENCIALIDAD

MÉDICA. ¿CÓMO

SE CONJUGAN

PARA ASEGURAR

LA SALUD DE LOS

ADOLESCENTES

PARENT'S

RESPONSIBILITY,

PROFESSIONAL

SECRECY AND

MEDICAL

CONFIDENTIALITY.

HOW DO THEY

COMBINE

TO ENSURE

ADOLESCENTS

HEALTH? 
b. si el secreto no existiese, el paciente no se acercaría al médico, no se curaría, y esto amenaza la salud pública. Lealtad y verdad son necesarias entre doctores y pacientes;

c. hay necesidad social en que ciertas profesiones tengan prestigio y sean respetadas por la sociedad de manera que inspiren en sus integrantes la confianza requerida para que tales profesiones funcionen apropiadamente.

En razón del interés social que encierra, la mayoría de los bioeticistas entiende que la regla de la confidencialidad médica es casi absoluta.

Sin embargo, no todos los médicos son conscientes de ese deber. Una encuesta realizada en Inglaterra por Wertz y Fletcher, en 1989, reveló que cerca del $60 \%$ de los genetistas de diversos países del mundo que respondieron estaban de acuerdo en revelar el dato a los parientes sin consentimiento del paciente; no hicieron distinción según que esa enfermedad fuese mortal, como el mal de Huntington, o no mortal, como la hemofilia. En Holanda, el 26\% de los médicos entrevistados estaba dispuesto a revelar el dato a familiares, sin el consentimiento del paciente, pero no a terceras personas, como patronal, aseguradora, etcétera ${ }^{16}$.

Verificando esa realidad en el ámbito de la práctica de la medicina, los eticistas norteamericanos dicen: muchas veces los médicos suponen, sin justificación, que los pacientes desean que su estado sea plenamente revelado a su familia. Es necesario alejarse de tal suposición ${ }^{17}$.

\section{HISTORIA DEL SECRETO PROFESIONAL MÉDICO ${ }^{18}$}

Los historiadores remontan el secreto a tiempos antiguos. Muchos recuerdan que aparece en el juramento de Hipócrates: «Lo que en el ejercicio de la profesión, y aun fuera de ella, viere u oyere acerca de la vida de las personas y que no deba ser divulgado, callaré considerando la discreción como un deber en semejantes casos» ${ }^{19}$.

Esos estudiosos relatan que el secreto médico era conocido antes de Hipócrates, pero no se relacionaba con la confidencialidad y a la intimidad,

16 Datos proporcionados por GILBAR, Roy. Ob. cit., p. 205.

17 Citado por HOERNI, Bernard \& Michel BÉNÉZECH. Ob. cit., p. 56.

18 Para el tema, ver ibídem, pp. 5-13.

19 OtERO GonzÁLEZ, María del Pilar. Ob. cit., p. 23; COSTA, María Victoria. «El manejo de la información médica. El consentimiento informado y la confidencialidad». En LUNA, Florencia \& Arleen SALLES. Bioética: nuevas reflexiones sobre debates clásicos. México D.F.: FCE, 2008, p. 183; LAMBERTI, Silvio \& Juan Pablo VIAR. «El profesional de la salud frente al secreto profesional». En BLANCO, Luis Guillermo, (comp.). Bioética y bioderecho. Cuestiones actuales. Buenos Aires: Universidad, 2002, p. 135; MARTínEZ MORÁN, Narciso. «La protección jurídica del derecho a la intimidad en el ámbito de las investigaciones biomédicas». En JUNQUERA DE ESTÉFANI, Rafael (dir.). Bioética y bioderecho. Reflexiones jurídicas ante los retos bioéticos. Granada: Comares, 2008, p. 113. 
sino con la transmisión de los conocimientos. $\mathrm{O}$ sea, el secreto se refería al que debían conservar los que practicaban la medicina (sacerdotes, hechiceros, adivinos, etcétera), respecto a sus saberes, que no debían informar a sus pacientes ${ }^{20}$. Después de Hipócrates, el secreto se evanesció, sin desaparecer completamente. En la Edad Media se reforzó al ser asimilado al principio más extendido del secreto de confesión. Después de la revolución francesa se puso nuevamente de relieve, a punto de ser un símbolo intocable del ejercicio médico, durante más de ciento cincuenta años. En la última mitad del siglo pasado retomó el camino que nunca debió dejar, cual es, ser considerado un medio de respeto de las personas y no un fin en sí mismo ${ }^{21}$.

\section{ASPECTOS QUE COMPRENDE EL SECRETO MÉDICO}

La información sometida al deber de sigilo médico comprende, entre otros, los siguientes aspectos: (a) el diagnóstico, pronóstico y terapia de la enfermedad del paciente; (b) otras circunstancias de la enfermedad: gravedad, complicaciones y otros hechos vinculados; (c) internación en establecimientos hospitalarios, etcétera ${ }^{22}$.

\section{NORMATIVA GENERAL}

El derecho al secreto médico está incluido, desde hace años, en los códigos de deontología médica. Así, por ejemplo, el artículo 11 del vigente en Francia dispone que el secreto profesional, instituido en el interés de los enfermos, se impone a todo médico en las condiciones establecidas por la ley. El secreto cubre todo aquello que ha llegado al conocimiento del médico en el ejercicio de su profesión, o sea, no solo aquello que se le ha confiado, sino todo lo que ha escuchado o comprendido.

Las denominadas leyes de «sanidad» de casi todos los países contienen una especie de catálogo de los derechos de los pacientes entre los cuales se incluye el derecho al secreto médico. Así, por ejemplo, la ley española 14/1986 dispone que «todos tienen los siguientes derechos con respecto a las distintas administraciones sanitarias: [...] a la confidencialidad de toda la información relacionada con su proceso y con su estancia en instituciones sanitarias públicas y privadas [...]».

En la República Argentina, el artículo 2 inciso c) de la ley 26.529 dispone: «Intimidad. Toda actividad médico-asistencial tendiente a obtener, clasificar, utilizar, administrar, custodiar y transmitir información y documentación clínica del paciente debe observar el estricto respeto por

20 SAYAGO, Roberto. «El secreto médico. Su evolución, los nuevos problemas y el marco actual de la bioética». Jurisprudencia Argentina, IV, 1273 (2001).

21 HOERNI, Bernard \& Michel BÉNÉZECH. Ob. cit., p. 5.

22 Verdú PASCUAL, Fernando. Ob. cit., p. 10.

RESPONSABILIDAD DE LOS PADRES,

SECRETO

PROFESIONAL Y

CONFIDENCIALIDAD

MÉDICA. ¿CÓMO

SE CONJUGAN

PARA ASEGURAR

LA SALUD DE LOS

ADOLESCENTES

PARENT'S

RESPONSIBILITY,

PROFESSIONAL

SECRECY AND

MEDICAL

CONFIDENTIALITY.

HOW DO THEY

COMBINE

TO ENSURE

ADOLESCENTS

HEALTH? 
la dignidad humana y la autonomía de la voluntad, así como el debido resguardo de la intimidad del mismo y la confidencialidad de sus datos sensibles, sin perjuicio de las previsiones contenidas en la ley 25.326».

El derecho aparece en numerosos documentos internacionales vinculados a los derechos humanos. Así, el artículo 10 del Convenio Europeo sobre los derechos humanos y la biomedicina, llamado Convenio de Oviedo de 1997, dispone: «Vida privada y derecho a la información. 1. Toda persona tendrá derecho a que se respete su vida privada cuando se trate de informaciones relativas a su salud».

El artículo 8 de la Declaración de los Derechos del Paciente, suscrita en Lisboa en 1981 y completada en Bali en 1994 dice:

Derecho al secreto profesional. a) Toda información identificable concerniente al estado de salud, las circunstancias médicas, el diagnóstico, el pronóstico, el tratamiento del paciente y toda otra información que le concierna, debe quedar confidencial, aun después de su muerte. Excepcionalmente, los descendientes pueden tener un derecho de acceso a las informaciones susceptibles de revelar riesgos que puedan correr en su salud. b) La información confidencial no puede ser divulgada excepto consentimiento expreso del paciente o que la ley lo autorice expresamente. La información no puede ser divulgada a otras personas excepto que acrediten la necesidad de saber; c) Todos los datos identificables concernientes al paciente deben ser protegidos. Esta protección debe corresponder a su forma de almacenamiento. Las substancias humanas a partir de las cuales estos datos son identificables deben ser igualmente protegidas.

La Declaración de Ginebra de la Asociación Médica Mundial, 19481968-1983, proclama la promesa del médico de «guardar y respetar los secretos a mí confiados, aun después de que un paciente haya muerto». El Código Internacional de Ética Médica, de la misma fuente, reitera: «El médico debe [...] salvaguardar las confidencias de los pacientes».

\section{SUJETO OBLIGADO}

El obligado a guardar el secreto es el médico. Esta afirmación merece algunas aclaraciones.

Las prácticas hospitalarias ponen barreras a veces insuperables a la eficacia del derecho al secreto. ¿Qué confianza puede tener el paciente internado en un hospital de que el secreto será guardado si es visitado no solo por el médico, sino por la pléyade de asistentes, estudiantes de la facultad, que lo acompañan en cortejo? ${ }^{23}$. 
El ejercicio de la medicina se hace paulatina y permanentemente más complejo en razón de los progresos de la ciencia y la tecnología, desarrollándose la medicina en equipo; la clásica relación entre dos personas (médico y paciente), que permitía con bastante seguridad la guarda y custodia del secreto profesional, se ha modificado profundamente. Cualquiera se sorprende al contabilizar el número de personas que pueden tener contacto con un enfermo internado; obviamente, el número aumenta cuando se impulsa la seguridad social y se generan nuevos sistemas de atención sanitaria ${ }^{24}$.

Además, actualmente, uno de los modos más frecuentes de violar la intimidad es a través del sistema informático organizado por los centros de salud ${ }^{25}$, razón por la cual, muchos países han regulado la protección de estos datos y la necesidad de preservar fuera de la información los llamados datos sensibles. Aun así, es indudable que el mayor riesgo para el secreto médico es hoy la informática ${ }^{26}$.

Por todo esto (el ejercicio grupal, prácticas frecuentes como consulta, la informatización, etcétera) hoy se habla del derecho al secreto compartido o participado (partagé, en francés). Cabe aclarar que aunque el concepto de secreto compartido fue elaborado hace muchos años, aún no tiene existencia en la mayoría de los textos legales, por lo que se afirma que se trata, todavía, del «hijo bastardo» ${ }^{27}$.

\section{SUJETO BENEFICIADO}

Como regla, el derecho al secreto médico está instituido a favor de los pacientes. Esta parece una verdad de Perogrullo, pero es necesario subrayarla, pues aunque hay un interés social en su respeto, los problemas deben ser resueltos teniendo en consideración el derecho humano de la persona a su ámbito de intimidad y reserva.

\section{SANCIÓN POR EL INCUMPLIMIENTO DE ESTAS OBLIGACIONES}

\section{XI.1. Principio general}

Establecer normativamente el deber del secreto profesional y sus alcances no es un tema baladí. Por el contrario, su violación trae sanciones, incluso penales en algunos ámbitos ${ }^{28}$.

24 SAYAGO, Roberto. Ob. cit.

25 Para el tema, ver Requejo NAveros, María Teresa. Ob. cit., pp. 34 y ss.

26 BARNI, Mauro. «I doveri del medico». En LENTI, Leonardo \& otros (eds.). Trattato di Biodiritto. I diritti in medicina. Milán: Giuffrè, 2011, pp. 161 y ss.

27 HOERNI, Bernard \& Michel BÉNÉZECH. Ob. cit., p. 53.

28 Ver, entre otros, REQUEJO NAVEROS, María Teresa. Ob. cit.

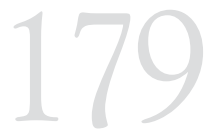

RESPONSABILIDAD

DE LOS PADRES,

SECRETO

PROFESIONAL Y

CONFIDENCIALIDAD

MÉDICA. ¿CÓMO

SE CONJUGAN

PARA ASEGURAR

LA SALUD DE LOS

ADOLESCENTES

PARENT'S

RESPONSIBILITY,

PROFESSIONAL

SECRECY AND

MEDICAL

CONFIDENTIALITY.

HOW DO THEY

COMBINE

TO ENSURE

ADOLESCENTS

HEALTH? 


\section{XI.2. Las sanciones penales}

La historia de la regulación penal por la violación del secreto profesional presenta dos tendencias:

Una propicia a la despenalización, por lo que menciona expresamente a los sujetos involucrados (eclesiásticos, abogados, médicos, boticarios, barberos, comadronas, etcétera), lo que implica que los no mencionados no cometen el delito ${ }^{29}$.

Otra sanciona de modo genérico la conducta del profesional de divulgar los secretos de otro, cualquiera que haya sido la forma de haberlos llegado a conocer. El distinto tratamiento que reciben los profesionales condujo a propiciar que se sancione, de modo genérico, «al profesional que revelare los secretos de un cliente de los que tuviere conocimiento por razón de su profesión u oficio».

Cualquiera sea la posición que se asuma, cabe recordar que el derecho penal es la última ratio. Se lee en el voto razonado de García Ramírez de la decisión de la Corte Interamericana de Derechos Humanos recaído en la causa De La Cruz Flores vs. Perú, fallado el 18 de noviembre de 2004:

La ley penal debe contemplar, para efectos punitivos, ciertas conductas que afectan gravemente los bienes jurídicos más relevantes. La idea de un Derecho penal mínimo, asociada al garantismo, que hoy enfrenta diversos embates, supone la incriminación de tales conductas ilícitas, habida cuenta de su gravedad y de la lesión que producen, cuando no se dispone de medios sociales o jurídicos alternos para evitarlas o sancionarlas. Bajo este concepto, la ley penal debe ser utilizada como último recurso del control social y concentrarse en esos comportamientos de gravedad extrema.

Por eso, si el código penal sanciona el atentado a la intimidad mediante la violación del secreto profesional es porque considera que se trata de una conducta grave; esta calificación deriva de los siguientes elementos: (i) el sujeto activo, especialmente si se trata de un profesional funcionario público, pues está en juego el correcto funcionamiento de la administración; (ii) la particular relación de confianza y necesidad que media entre el sujeto activo y la víctima; (iii) el bien jurídico que se protege (la defensa de la intimidad como derecho de la personalidad) ${ }^{30}$.

29 Paralelamente, algunos códigos de procedimiento individualizan qué profesionales no están obligados a declarar, lo que implica que los demás deben hacerlo. Así, por ejemplo, el artículo 141 del Código de Procedimientos Penales del Perú dispone que «no podrán ser obligados a declarar: 1. los eclesiásticos, abogados, médicos, notarios y obstétricas, respecto de los secretos que se les hubiera confiado en el ejercicio de su profesión».

30 Otero GonzÁlez, María del Pilar. Ob. cit., p. 6. 
Así, en el título relativo a los delitos contra la libertad, en el capítulo III, el código penal argentino regula la «Violación de Secretos y de la Privacidad» y el artículo 156 dispone: «Será reprimido con multa de pesos mil quinientos a pesos noventa mil e inhabilitación especial, en su caso, por seis meses a tres años, el que teniendo noticia, por razón de su estado, oficio, empleo, profesión o arte, de un secreto cuya divulgación pueda causar daño, lo revelare sin justa causa».

De cualquier modo, las sentencias que sancionan penalmente a los médicos por violación del secreto son escasas. Cabe recordar una decisión interesante del Tribunal Supremo Español del 4 de abril de 2001 que condenó a una médica a un año de prisión, a una multa e inhabilitación especial para el ejercicio de su profesión por dos años (la pena mínima) y a reparar los daños causados. Los hechos eran los siguientes: en un hospital, la profesional de la salud atendió a una mujer a quien conocía por provenir ambas de un pequeño pueblo. De la historia clínica, la profesional extrajo el dato de que la paciente estaba embarazada y que había tenido dos abortos anteriores. La médica reveló este secreto a la hermana de la gestante quien, en realidad, ya lo conocía de antes. El Tribunal Supremo revocó la absolución de los jueces de grado que entendieron que lo revelado era asimilable a las noticias que publica la prensa amarilla. La sentencia condenatoria argumentó que para diferenciar la conducta típica de la mera indiscreción es necesario que lo comunicado afecte a la esfera de la intimidad que el titular quiere defender, y que lo manifestado por el tribunal de grado frivolizaba sentimientos de modo no ajustado a la realidad.

\section{XI.3. El derecho penal, el deber de denunciar del funcionario público y el delito de aborto}

Como he adelantado, uno de los conflictos que tiene llegada a la justicia con mayor frecuencia es el de la oposición entre deber de denunciar y violación al deber de secreto. En efecto, por un lado, la ley penal reprime la violación del secreto profesional; por el otro, obliga a denunciar a los que «por razón de sus cargos, profesiones u oficios tuvieren noticia de algún delito público».

Los médicos de los hospitales de los países que penalizan la interrupción del embarazo tienen el problema de esa confrontación. Por el contrario, los de los países que autorizan el aborto no tienen dificultad alguna en reconocer que existe deber de mantener el secreto médico ${ }^{31}$.

RESPONSABILIDAD

DE LOS PADRES,

SECRETO

PROFESIONAL Y

CONFIDENCIALIDAD

MÉDICA. ¿CÓMO

SE CONJUGAN

PARA ASEGURAR

LA SALUD DE LOS

ADOLESCENTES

PARENT'S

RESPONSIBILITY,

PROFESSIONAL

SECRECY AND

MEDICAL

CONFIDENTIALITY.

HOW DO THEY

COMBINE

TO ENSURE

ADOLESCENTS

HEALTH? 
En Argentina, la sentencia plenaria recaída en la causa Natividad Frías de la Cámara Nacional de Apelaciones en lo Criminal y Correccional de Capital Federal, del 26 de agosto de 1966, decidió por nueve votos contra ocho que:

No puede instruirse sumario criminal en contra de una mujer que haya causado su propio aborto o consentido en que otro se lo causare, sobre la base de la denuncia efectuada por un profesional del arte de curar que haya conocido el hecho en ejercicio de su profesión o empleo —oficial o no- pero sí corresponde hacerlo en todos los casos respecto de sus coautores, instigadores o cómplices.

Esta posición, que personalmente comparto, se funda en las siguientes razones:

(i) «La mera presencia ante el médico de la mujer autora o coautora de su propio aborto implica una auto-acusación forzada por la necesidad impuesta por el instinto natural de la propia conservación puesto que acude a él en demanda angustiosa de auxilio para su salud y su vida. No es, pues, posible, admitir que una auto-acusación de índole semejante sea jurídicamente admisible para pronunciarse a favor de la prevalencia del interés social de reprimir el delito, con desmedro del superior derecho humano a la subsistencia y con menoscabo del principio que informa la norma constitucional citada (artículo $18 \mathrm{CN}$ ). Si nadie está obligado a declarar contra sí mismo [...] menos puede estarlo a sufrir las consecuencias de una autoacusación impuesta por necesidad insuperable».

(ii) La colisión entre la obligación de mantener el secreto profesional y el deber de los médicos de hacer conocer a la autoridad los delitos de los que tuvieren conocimiento en ejercicio de sus funciones es superada entendiendo que las manifestaciones de la paciente respecto de su aborto no alcanzan a configurar la «justa causa» que el Código reclama para justificar la violación del secreto profesional. Esta causa es exclusivamente legal. Es decir, que solo una ley puede eximir de guardar el secreto debido, convirtiendo en obligación su quebranto.

(iii) La posición contraria obliga a la mujer a elegir entre la disyuntiva «morir o ir a la cárcel».

El maestro Bidart Campos dio valioso apoyo a la solución, con estos argumentos:

No dudamos que el médico que bajo revelación del enfermo toma conocimiento del aborto no puede denunciar el delito. Se lo impide 
el secreto profesional, que para nosotros tiene seguro arraigo constitucional en el derecho a la intimidad o privacidad. El médico no puede disponer, a su criterio, de ese secreto. O sea, no puede optar entre guardarlo o hacerlo público, porque en la relación de privacidad entre él y el paciente tiene el deber constitucional de abstenerse de revelar lo que supo bajo secreto profesional. Es por eso ortodoxo nulificar los testimonios de la mujer abortada y de su madre, por cuanto sus respectivas declaraciones bajo juramento de decir verdad encierran autoinculpación, con alcance incompatible respecto de la inmunidad de declarar contra sí mismo que concede el art. 18 de la $\mathrm{CN}^{32}$.

No obstante, las discrepancias continúan. Algunos jueces, aun perteneciendo al mismo ámbito del tribunal que dictó el plenario, se rebelan y resuelven lo contrario sobre la base de inexistentes particularidades del caso. En este sentido, se afirma que,

[...] la presentación de una persona en un hospital revelando haber cometido un aborto o consentido que otro lo causare no implica autoacusación forzada para preservar su vida, sino el desenlace en todo caso natural de una acción ilícita que habría sido ejecutada conociendo los riesgos que previsiblemente podrían afrontarse. La comunicación del aborto a la autoridad policial efectuada por el médico de la paciente no es típica del delito de violación de secretos, no solo porque no impone un daño en el sentido de injusta afectación de bienes jurídicos amparables, sino también porque existe justa causa de revelación ${ }^{33}$.

Más aun, un tribunal superior de provincia, me refiero a la Corte Suprema de Justicia de la provincia de Santa Fe, el 12 agosto de $1998^{34}$ decidió:

Los profesionales que presten servicios en instituciones privadas no están exentos del deber de denunciar los hechos ilícitos que pudieran llegar a su conocimiento. Ello es así pues además de la normativa adjetiva que les impone tal comportamiento, se ven compelidos por lo previsto en el art. 277 del CPP en cuanto prevé la figura

32 BIDART CAmpos, Germán. Denuncia de aborto y secreto profesional del médico. ED 166-224.

33 Ver sentencia de la Sala Séptima en el caso G.N. del primero de abril de 2007, con nota crítica de Gulco, Hernán. "La tutela de la intimidad y el rechazo de "Natividad Frías" ". Jurisprudencia Argentina, IV, 295 (2007). En la sentencia se encuentran amplias referencias a la jurisprudencia en uno y otro sentido. Algunas motivaciones son muy interesantes, pero, lamentablemente, la regla que formula luego se aplica mal. Así, por ejemplo, se afirma: «Los derechos constitucionales no son gallos de pelea; debe partirse de la unidad de los derechos fundamentales, en una visión tendiente a su concreta armonización». Las distintas posiciones jurisprudenciales también se reseñan en CEPEDE, Analía de los Ángeles. Ob. cit. (la posición que adopta la autora no es clara; parece compartir el criterio mayoritario de la Suprema Corte de Santa Fe).

34 LL 1998-F-545, con nota desaprobatoria de BIDART CAMPOS, Germán. Deber de denuncia penal y secreto profesional del médico. Entre medio: aborto, vida, salud, igualdad. ED 179-191 y en Foro de Córdoba 54-179, y de GIL DomínGUEZ, Andrés. Aborto voluntario: la constitucionalización de la pobreza.

RESPONSABILIDAD

DE LOS PADRES,

SECRETO

PROFESIONAL Y

CONFIDENCIALIDAD

MÉDICA. ¿CÓMO

SE CONJUGAN

PARA ASEGURAR

LA SALUD DE LOS

ADOLESCENTES

PARENT'S

RESPONSIBILITY,

PROFESSIONAL

SECRECY AND

MEDICAL

CONFIDENTIALITY.

HOW DO THEY

COMBINE

TO ENSURE

ADOLESCENTS

HEALTH? 
de encubrimiento y por las leyes específicas que regulan el ejercicio de las ramas del arte de curar en nuestro país ${ }^{35}$.

Bidart Campos criticó con su habitual agudeza los argumentos del voto mayoritario:

[...] la vida en gestación que se había destruido con el aborto ya no podía protegerse en el caso, porque el nasciturus no existía. Ergo, el conflicto verdadero que con realismo tenía que resolverse no incluía la protección a la vida en gestación de un ser al que el aborto había eliminado. Un criterio de eficacia, unido a un juicio de previsibilidad sobre las consecuencias del fallo parece decirnos que, desde el plano del derecho constitucional, la política criminal y la legislación penal consecuente, no han de trasladarse a las mujeres pobres el riesgo de la persecución penal por el delito de aborto ya consumado, porque el secreto médico y la vida o salud de la madre colocan en un nivel más alto y más valioso la obligación (también constitucional) del Estado (incluidos los jueces) y de los profesionales del arte de curar, de promover la igualdad real de oportunidades y de trato mediante las prestaciones de salud a favor de todas las mujeres, incluidas las que han abortado. No nos olvidemos que el art. 75 inc. 23, después de instar a la igualdad, particulariza cuatro grupos humanos en especial, y dentro de ellos, menciona a las mujeres.

En Argentina, la cuestión debe considerarse definitivamente zanjada por la Corte Federal en el caso Baldivieso, César Alejandro, del 20 de abril de 2010 que ratificó el criterio del plenario Natividad Frías en el caso de un imputado por el delito de tráfico de drogas que concurrió a un hospital público, frente al grave riesgo que significaba portar esa droga dentro de su cuerpo.

En el resto de América Latina, el debate también debe estimarse cerrado tan pronto los jueces nacionales apliquen la jurisprudencia de la Corte Interamericana de Derechos Humanos, que en el caso De La Cruz Flores vs. Perú, fallado el 18 de noviembre de 2004, aceptó la tesis según la cual «Perseguir penalmente actividades profesionales lícitas, so pretexto de combatir el terrorismo, vulnera el artículo nueve de la Convención Americana, al penalizar un hecho lícito: la actividad médica».

35 El artículo 277 del Código Penal ubicado en el capítulo «Encubrimiento» dispone: 1. Será reprimido con prisión de seis (6) meses a tres (3) años el que, tras la comisión de un delito ejecutado por otro, en el que no hubiera participado:

a) Ayudare a alguien a eludir las investigaciones de la autoridad o a sustraerse a la acción de esta.

b) Ocultare, alterare o hiciere desaparecer los rastros, pruebas o instrumentos del delito, o ayudare al autor o partícipe a ocultarlos, alterarlos o hacerlos desaparecer.

c) Adquiriere, recibiere u ocultare dinero, cosas o efectos provenientes de un delito.

d) No denunciare la perpetración de un delito o no individualizare al autor o partícipe de un delito ya conocido, cuando estuviere obligado a promover la persecución penal de un delito de esa índole.

e) Asegurare o ayudare al autor o partícipe a asegurar el producto o provecho del delito. 
Si el médico puede asistir al terrorista herido y guardar silencio sobre ese acto, con mayor razón puede y debe asistir a una mujer que se ha sometido a un aborto clandestino y concurre a un centro de salud para ser asistida. Recuérdese que en este caso, el Tribunal Constitucional del Perú había justificado la sanción con el siguiente argumento:

[...] respecto de los médicos cuya responsabilidad está acreditada, si bien como profesional de la salud estaban obligados a usar su ciencia a favor de quien la necesita, sin distinción alguna, velando por la vida humana, haciendo caso omiso a credos políticos religiosos, las sindicaciones contra ellos no son simplemente por haber actuado como médicos en favor de elementos terroristas, pues de ser así, no sería delito, sino que cuando un galeno tiene la simple presunción o el conocimiento del origen ilícito de las lesiones causadas a un individuo, está obligado a denunciar el hecho o ponerlo en conocimiento de las autoridades para que realicen las investigaciones respectivas.

O sea, según el tribunal peruano, el médico tiene ambas obligaciones: asistir y denunciar.

La Corte Interamericana respondió categóricamente con el artículo 18 del I Convenio de Ginebra de 1949, que señala que «Nadie podrá ser molestado o condenado por el hecho de haber prestado asistencia a heridosoa enfermos», y con el artículo 16 del Protocolo Iy el artículo 10 del Protocolo II, ambos Protocolos a los Convenios de Ginebra de 1949, que disponen que «No se castigará a nadie por haber ejercido una actividad médica conforme con la deontología, cualesquiera hubieran sido las circunstancias o los beneficiarios de dicha actividad». Concretamente, en el parágrafo 97 de la decisión se lee: «la información que el médico obtiene en ejercicio de su profesión se encuentra privilegiada por el secreto profesional». Por ejemplo, el Código Internacional de Ética Médica de la Asociación Médica Mundial dispone que:

[...] el médico debe guardar absoluto secreto de todo lo que se le haya confiado, incluso después de la muerte del paciente [...] En consecuencia, a la luz de las consideraciones precedentes, el Tribunal estima que el Estado peruano incurrió en una violación del principio de legalidad, por [...] penalizar el acto médico que no solo es un acto esencialmente lícito, sino que es un deber de un médico el prestarlo; y por imponer a los médicos la obligación de denunciar posibles conductas delictivas de sus pacientes con base en la información que obtengan en el ejercicio de su profesión.

El voto razonado del juez García Ramírez agrega:

8. El Estado no puede vulnerar la protección de la salud y la vida que los médicos tienen a su cargo, a través de normas o interpretaciones 
de estas que disuadan al médico de cumplir su deber, sea porque lo amenacen con la aplicación de una pena, amenaza que pudiera inhibir la prestación del servicio médico, sea porque lo induzcan a hacer distinciones contrarias a los principios de igualdad y no discriminación, sea porque lo obliguen a desviarse de la función que les corresponde y asumir otra, que entre en conflicto con aquella, proponga dilemas inaceptables o altere de raíz la relación entre el médico y el paciente, como sucedería si se obligara al médico a constituirse en denunciante $\multimap$ o delator- de los pacientes que atiende. Otro tanto sucedería, en su propio ámbito, si se forzara al abogado a denunciar los hechos ilícitos en que ha incurrido su cliente, de los que se entera a través de la relación de asistencia y defensa, o al sacerdote a revelar los secretos que le son confiados por medio de la confesión.

9. En ningún caso se trata de impedir la persecución legítima de conductas ilícitas, que deben ser combatidas por medios idóneos, sino de mantener cada relación social en el cauce que le corresponde, no solo para bien privado, sino también —y quizás ante todo— para bien público. El fiscal y el investigador deben llevar adelante las indagaciones a las que se hallan obligados, en virtud de la función que ejercen. El médico, el abogado defensor, el sacerdote deben hacer otro tanto, con plena salvaguarda del Estado, en el ejercicio de la misión que les incumbe y que ciertamente no es la investigación de los delitos y la persecución de los infractores. Sobra describir la crisis que traería consigo la subversión de los roles profesionales y sociales y la tácita incorporación de médicos, defensores y sacerdotes a las filas de la policía. Si se protege la comunicación confidencial entre el abogado y el inculpado, que está al abrigo de interferencias, y se concede que el sacerdote no está obligado a violar el secreto de confesión —que constituye, inclusive, un rasgo esencial de esta comunicación específica, que los creyentes consideran sacramental— la misma consideración, por lo menos, se debe poner en la relación entre el médico y el enfermo.

\section{EL SECRETO MÉDICOY LOS NIÑOS, NIÑASY ADOLESCENTES \\ XII. 1. La situación de los adolescentes en la región \\ Intento, de aquí en adelante, trasladar los principios generales sobre el secreto médico a la situación de los adolescentes. La cuestión es cuantitativa y cualitativamente muy importante.}

La población joven de entre 10 y 24 años representa el 24,5\% de la población de América. En América Latina y el Caribe hay más de 100 millones de adolescentes de entre 10 y 18 años. Esta cifra es la más alta en la historia de la región, lo cual implica un cambio en la estructura de edades. Esto aporta muchos beneficios, pero también casi 
el mismo número de desafíos. En América Latina, aproximadamente 58 millones (41\% de los jóvenes) viven en la pobreza y el $22 \%$ de aquellos que viven en pobreza extrema tienen entre 13 y 19 años de edad.

Con esos índices, no debe extrañar que se registre la segunda tasa más alta de embarazos adolescentes del mundo. Un promedio de $38 \%$ de las mujeres se embarazan antes de cumplir los 20 años. Casi el $20 \%$ de nacimientos vivos son de madres adolescentes. Entre las que se encuentran en situación de pobreza, la fecundidad es tres veces más alta que en el resto; el uso de los métodos anticonceptivos es menor y tienen más probabilidad de dar a luz antes de los 20 años ${ }^{36}$.

Se advierte, pues, un círculo vicioso entre exclusión social y fecundidad adolescente, en la medida en que esta se produce especialmente en mujeres de escasos recursos y con bajo nivel educativo. El embarazo adolescente afecta el desarrollo de las mujeres jóvenes y sus hijos e hijas tanto en el ámbito de la salud, como en la inclusión social, en la educación y en el trabajo ${ }^{37}$.

Según la Organización Mundial de la Salud, cerca de dos tercios de muertes prematuras ente los adultos están ligadas a afecciones contraídas o a comportamientos adoptados durante la infancia y la adolescencia. Esta situación debería ser, entonces, una preocupación central de las políticas de salud pública. En un mundo en el que la juventud tiene dificultades para encontrar su lugar, en el que ella es la primera víctima de las crisis sociales o humanitarias, nuestro deber es comprometernos a fin de proteger su salud y garantizar sus derechos como persona ${ }^{38}$.

\section{XIII.PRIMER PUNTO DE PARTIDA: PRESENCIA DE UN MENOR COMPETENTE, AUTÓNOMO}

Como es sabido, la conciencia del propio cuerpo llega a cada ser humano mucho antes que su mayoría de edad; si se puede poner sobre la mesa la voluntad del niño cuando se trata de su cuerpo es, precisamente, porque es «sobre su cuerpo que el espíritu se despierta primero y pronto» ${ }^{39}$.

De allí que todas las referencias que siguen a continuación se refieren al adolescente, o al llamado «menor maduro» (mineur mûr, mature minor) o competente, o con autonomía suficiente para comprender el acto médico ${ }^{40}$.

36 Cepal. Objetivos de desarrollo del milenio: una mirada desde América Latina y el Caribe. UNICEF, 2005 (www.unicef.org/lac/Fast_facts_SP(1)pdf).

37 MORLACHETTI, Alejandro. "Adolescencia y juventud: sus derechos sexuales y reproductivos». Jurisprudencia Argentina, II, 1233 (2011).

38 Bachelot-NARQUin, Roslyne. Prólogo. En FeUILLET-LIGER, Brigitte \& Ryuichi IDA. Ob. cit., p. 1.

39 CORNu, Gerard. Prólogo. En DuvAl-ARNOULD, Domitille. Ob. cit., p. xvi.

40 Para estas nociones, desarrolladas en Inglaterra a partir del caso Gillik, ver de mi autoría, «El derecho del menor sobre su propio cuerpo». En BORDA, Guillermo (dir.). La persona humana. Buenos Aires:

RESPONSABILIDAD DE LOS PADRES, SECRETO PROFESIONAL Y CONFIDENCIALIDAD MÉDICA. ¿CÓMO SE CONJUGAN PARA ASEGURAR LA SALUD DE LOS ADOLESCENTES

PARENT'S

RESPONSIBILITY, PROFESSIONAL SECRECY AND MEDICAL CONFIDENTIALITY. HOW DO THEY COMBINE TO ENSURE ADOLESCENTS HEALTH? 


\section{SEGUNDO PUNTO DE PARTIDA. EL INTERÉS SUPERIOR DEL NIÑO}

Toda solución debe estar presidida por un principio básico de la Convención Internacional de los Derechos del Niño. Obviamente, me refiero al interés superior del niño previsto, específicamente, en el artículo 3 que dice: «1. En todas las medidas concernientes a los niños que tomen las instituciones públicas o privadas de bienestar social, los tribunales, las autoridades administrativas o los órganos legislativos, una consideración primordial a que se atenderá será el interés superior del niño».

Si el interés superior del niño consiste, como dice el artículo 3 de la ley argentina 26.061, en la «máxima satisfacción, integral y simultánea de los derechos y garantías reconocidos en esta ley», es imprescindible hacer un muestreo de qué derechos tiene el niño vinculados a su cuerpo, pues toda solución debe respetarlos.

a. El artículo 16 de la Convención dice: «1. Ningún niño será objeto de injerencias arbitraria o ilegales en su vida privada, su familia, su domicilio o su correspondencia, ni de ataques ilegales a su honra y a su reputación. 2. El niño tiene derecho a la protección de la ley contra esas injerencias o ataques». El artículo 10 de la ley 26.061 dispone de modo coincidente: «Derecho a la vida privada e intimidad familiar. Las niñas, niños y adolescentes tienen derecho a la vida privada e intimidad de y en la vida familiar. Estos derechos no pueden ser objeto de injerencias arbitrarias o ilegales».

b. Los artículos 25 y 26 de la Convención dicen:

Los Estados partes reconocen el derecho del niño que ha sido internado en un establecimiento por las autoridades competentes para los fines de atención, protección o tratamiento de su salud física o mental a un examen periódico del tratamiento a que esté sometido y de todas las demás circunstancias propias de su internación.

$[\ldots]$

1. Los Estados partes reconocerán a todos los niños el derecho a beneficiarse de la seguridad social, incluso del seguro social, y adoptarán las medidas necesarias para lograr la plena realización de este derecho de conformidad con su legislación nacional. 2. Las prestaciones deberían concederse, cuando corresponda,

La Ley, 2001, p. 249, y « Seminario Internacional en Minoridad y Familia». Mendoza, 2001, p. 7. En Berget, Salvador \& Nelly MinYERSKY, (coords.). Bioética y derecho. Santa Fe: Rubinzal, 2003, p. 105; y en DINIZ, Maria Helena \& Roberto Senise LISBOA (coords.). O Direito Civil no Século XXI. São Paulo: Saraiva, 2003, p. 1. 
teniendo en cuenta los recursos y la situación del niño y de las personas que sean responsables del mantenimiento del niño, así como cualquier otra consideración pertinente a una solicitud de prestaciones hecha por el niño o en su nombre.

Coincidentemente, el artículo 22 de la ley 26.061 menciona expresamente: «Derecho a la dignidad. Las niñas, niños y adolescentes tienen derecho a ser respetados en su dignidad, reputación y propia imagen».

a. El artículo 2 inciso c) de la ley 26.529 de los derechos del paciente, referido al derecho del paciente a aceptar o rechazar determinadas terapias o procedimientos médicos o biológicos y a revocar posteriormente su manifestación de voluntad, agrega: «Los niños, niñas y adolescentes tienen derecho a intervenir en los términos de la ley 26.061 a los fines de la toma de decisión sobre terapias o procedimientos médicos o biológicos que involucren su vida o salud» ${ }^{41}$.

\section{TERCER PUNTO DE PARTIDA. EL DERECHO DEL NIÑO MADURO FRENTE A SUS REPRESENTANTES}

La normativa antes citada nos lleva al convencimiento de que todo niño tiene derecho a su dignidad, a su intimidad y, en consecuencia, todo lo dicho respecto al secreto de los adultos no debería ser diferente para los niños. Al contrario, estos derechos deberían estar profundizados en tanto el niño tiene derecho a un plus, a más derechos, precisamente por su situación de vulnerabilidad ${ }^{42}$.

La cuestión planteada, entonces, es cómo se aplica este secreto cuando el niño maduro pide que determinados datos no sean revelados a sus representantes o guardadores. En otras palabras, el tema es si el niño o adolescente maduro, competente, autónomo, tiene derecho al secreto médico aun frente a sus representantes legales ${ }^{43}$. La cuestión no es fácil de resolver; parafraseando a Kornprost podría decirse que es «una zona de sombras, en la que el Derecho no la pasa bien» ${ }^{44}$.

41 Un análisis de esta norma puede verse en FERNÁNDEZ, Silvia. «Los derechos de niños y adolescentes en el ámbito de la salud y del cuidado del propio cuerpo. Una aproximación a la cuestión frente a la ley 26.529 de Derechos del Paciente». Jurisprudencia Argentina, III, 928 (2010).

42 Ver, por ejemplo, GARcía NORIEGA, Antonio. Límites a la libertad de expresión por motivos profesionales. Madrid: Grupo Difusión, 2009, pp. 219-315; el autor desarrolla la cuestión bajo el título «La protección de la infancia y de la juventud como límite a la libertad de expresión».

43 No me refiero, por lo tanto, al derecho de los padres a controlar la correspondencia de sus hijos y, consecuentemente, respetar el secreto que ella encierra (para este tema, en España, ver CoRcoY BIDASOLO, Mirentxu. Ob. cit., p. 313).

44 Kornprost, Louis. Citado en Duval-Arnould, Domitille. Ob. cit., p. 81.

RESPONSABILIDAD

DE LOS PADRES,

SECRETO

PROFESIONAL Y

CONFIDENCIALIDAD

MÉDICA. ¿CÓMO

SE CONJUGAN

PARA ASEGURAR

LA SALUD DE LOS

ADOLESCENTES

PARENT'S

RESPONSIBILITY,

PROFESSIONAL

SECRECY AND

MEDICAL

CONFIDENTIALITY.

HOW DO THEY

COMBINE

TO ENSURE

ADOLESCENTS

HEALTH? 


\section{EL DERECHO AL SECRETO DEL ADOLESCENTE. DOS POSICIONES ENCONTRADAS}

Como en muchos ámbitos del derecho, existen, como mínimo, dos posiciones opuestas que, sin embargo, se encuentran en muchos puntos; esencialmente, cuando una y otra reconocen excepciones a la regla.

\section{FUNDAMENTOS DE LA TESIS NEGATIVA, O SEA, LA QUE SOSTIENE QUE LA PERSONA MENOR DE EDAD, AUN MADURA O COMPETENTE, NO TIENE DERECHO AL SECRETO PROFESIONAL FRENTE A SUS REPRESENTANTES LEGALES}

Esta posición argumenta de la siguiente manera:

a. El cliente del médico es incapaz, tiene representantes; por lo tanto, no se puede sancionar al galeno por haber comunicado lo que le ocurre al incapaz a esos representantes.

b. La obligación del representante es cuidar a la persona incapaz; debe presumirse que la revelación del secreto será en el propio interés del menor, en tanto permitirá al médico explicar y aconsejar a los representantes, sobre todo cuando el joven no puede mensurar la gravedad de su estado.

c. Este efecto es especialmente aplicable tratándose de enfermedades genéticas, en tanto los integrantes de la familia pueden llegar a ser la fuente mayor de confort del paciente.

d. El niño es incapaz para contratar; el médico tiene derecho a percibir sus honorarios; solo puede reclamárselos a los representantes legales, por lo que no le queda otra posibilidad que revelarles el secreto para poder cobrar lo que legítimamente le pertenece.

e. La posición que sostiene que no se debe revelar el secreto ni siquiera a los parientes implica una posición liberal individualista; la confidencialidad se basa en la percepción según la cual el paciente es visto como alguien separado de los otros o libre de los constreñimientos sociales. Muy por el contrario, la familia juega un importante rol, especialmente cuando el paciente no tiene suficiente competencia para tomar decisiones. 


\section{FUNDAMENTOS DE LA TESIS POSITIVA, O SEA, LA QUE SOSTIENE QUE LA PERSONA MENOR DE EDAD MADURA O COMPETENTE TIENE DERECHO AL SECRETO PROFESIONAL TAMBIÉN EN CONTRA DE SUS REPRESENTANTES 45}

Esta tendencia, predomina en la mayoría de los países, razona de la siguiente manera:

a. Las libertades fundamentales de la persona menor de edad, entre las cuales se encuentra su intimidad, tienen también eficacia directa en las relaciones paterno-filiales ${ }^{46}$.

b. La persona menor de edad puede tener secretos, aun cuando sea un incapaz para contratar. Puede ser que los comparta con una persona de confianza y no con sus representantes legales; por eso, las leyes más modernas de salud autorizan al adolescente a concurrir a peticionar el servicio con esa persona de confianza (por ejemplo, ley belga del 22 de agosto de 2002) ${ }^{47}$.

c. El interés del menor puede estar en guardar el secreto profesional. Se reconoce que el interés superior del niño es un concepto fluido y variable, difícil de definir y, después de todo, pertenece en primer lugar a los padres apreciar qué es mejor para su hijo. Sin embargo, tratándose de salud, esto no siempre es así; hay enfermedades o situaciones atingentes al cuerpo que, sin ser una enfermedad, generan en los padres grandes sufrimientos que pretenden apagar invadiendo el cuerpo del niño, como son las mutilaciones en adolescentes hermafroditas o pseudo hermafroditas y otros tipos de personas transgénero. Es importante disuadir al adolescente para que revele a los padres lo que le sucede, especialmente tratándose de enfermedades vinculadas a la salud psíquica (bulimia, anorexia, etcétera). Pero si después de los mejores esfuerzos médicos, el adolescente le pide que no revele la enfermedad, la conducta contraria del médico puede ser vista como una traición, el paciente pierde confianza en el médico, y una consecuencia frecuente es el abandono del tratamiento.

d. Revelar el secreto puede significar conflictos familiares muy graves; por ejemplo, en el caso de manifestar a una familia muy religiosa que la hija mujer ha perdido la virginidad. Más aún, en algunos casos, esta información puede haber sido pedida por los propios padres para cumplir con una convención fundada en las costumbres. Piénsese también en el testigo de Jehová

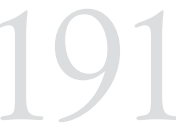

RESPONSABILIDAD

DE LOS PADRES,

SECRETO

PROFESIONAL Y

CONFIDENCIALIDAD

MÉDICA. ¿CÓMO

SE CONJUGAN

PARA ASEGURAR

LA SALUD DE LOS

ADOLESCENTES

PARENT'S

RESPONSIBILITY,

PROFESSIONAL

SECRECY AND

MEDICAL

CONFIDENTIALITY.

HOW DO THEY

COMBINE

TO ENSURE

ADOLESCENTS

HEALTH? 
que no quiere revelar a los padres la enfermedad que exige una transfusión sanguínea, y otros supuestos que enfrentan al adolescente con creencias de sus padres que él no siempre comparte. Teniendo en cuenta estos casos y otros análogos, la Observación General 12 del Comité de los Derechos del Niño (ONU) sobre el derecho del niño a ser escuchado CRC/C/GC/12 - primero de julio de 2009, dice: «Es necesario que los Estados introduzcan normas para garantizar el acceso de los niños al asesoramiento y consejo médico confidencial sin el consentimiento de los padres, independientemente de la edad del niño, en los casos que sea necesario para la protección de la seguridad o el bienestar del niño».

e. El reconocimiento del derecho al secreto médico camina a la par de la evolución del estatuto del niño. Como paciente, él tiene derecho al secreto médico; de allí que lo deseable es que el médico pueda administrar el tratamiento sin informar a los padres si el adolescente maduro así lo reclama.

f. Se reconoce, sin embargo, que en las legislaciones que no establecen una edad para el acto médico, (por ejemplo, 16 años), quien juzga si el adolescente tiene o no autonomía es el médico; por lo tanto, si considera que no tiene madurez, avisará a los padres.

\section{LA TESIS POSITIVA EN LA DECLARACIÓN DE OTTAWA} La Declaración de Ottawa sobre la Salud del Niño, adoptada por la Quincuagésima Asamblea Médica Mundial (AMM), Ottawa, Canadá, octubre de 1998 y enmendada por la Sexagésima Asamblea General de la AMM, Nueva Delhi, India, octubre de 2009, dice:

Los principios de esta Declaración se aplican a todos los niños del mundo desde su nacimiento hasta la edad de 18 años, sin consideración de raza, edad, etnia, nacionalidad, afiliación política, credo, idioma, sexo, enfermedad o discapacidad, capacidad física, mental, orientación sexual, historia cultural, experiencia de vida o posición social del niño o de sus padres o representantes legales. En todos los países del mundo, sin considerar los recursos, cumplir estos principios debe ser una prioridad para los padres, comunidades y gobiernos. La Convención de las Naciones Unidas sobre los Derechos del Niño (1989) establece los derechos de todos los niños y jóvenes, pero estos derechos no pueden existir sin la salud. 
$\mathrm{Al}$ enunciar los principios generales declara:

3. Una amplia gama de recursos de salud para todos significa:

El interés superior del niño será el criterio principal en la prestación de atención médica [...] j) El consentimiento informado es necesario antes de iniciar cualquier procedimiento diagnóstico, terapéutico, rehabilitador o de investigación en un niño. En la mayoría de los casos, el consentimiento debe obtenerse de los padres o representante legal, o en algunos casos, de la familia, aunque los deseos de un niño competente deben tomarse en cuenta antes de otorgar el consentimiento.

4. Las acciones de investigación y monitoreo para un mejoramiento continuo incluyen [...] e) La privacidad del paciente niño será respetada.

Los principios específicos que surgen de los documentos que sirvieron de base a este dicen, entre otros aspectos:

Dignidad del paciente

a) Todo paciente niño debe ser tratado en todo momento con respeto a su dignidad e intimidad.

b) Los médicos y otros trabajadores de la salud deben mantener la confidencialidad y la información sobre los pacientes niños como si fuesen adultos.

c) El paciente niño suficientemente maduro para realizar una consulta no acompañado por sus padres oguardianes tiene derecho a la intimidad y deben prestárseles servicios confidenciales. Su pedido debe ser respetado y la información obtenida durante esa consulta o la sesión de consejos no puede ser revelada a los padres o representantes, excepto con el consentimiento del niño. Si el médico no comparte el pedido del niño por razones religiosas o morales, el niño debe ser derivado a otro médico para la consulta, el consejo o el tratamiento.

La confidencialidad hacia el niño maduro puede no respetarse si es para denunciar abusos o abandonos, o si está en eminente riesgo de muerte o de seria y permanente discapacidad ${ }^{48}$. Obviamente, si estos abusos o abandonos provienen de la propia familia, el levantamiento del secreto

48 Un resultado similar se deriva del artículo 226-13 del Código Penal francés, que reprime la violación del secreto profesional, salvo que se trate, para el médico, de revelar la existencia de privaciones o ataques a menores de quince años. La doctrina señala que la norma no distingue expresamente según que el servicio sea requerido por un tercero o por el propio menor (DUVAL-ARNOULD, Domitille. Ob. cit., p. 142).

RESPONSABILIDAD DE LOS PADRES,

SECRETO

PROFESIONAL Y

CONFIDENCIALIDAD

MÉDICA. ¿CÓMO

SE CONJUGAN

PARA ASEGURAR

LA SALUD DE LOS

ADOLESCENTES

PARENT'S

RESPONSIBILITY,

PROFESSIONAL

SECRECY AND

MEDICAL

CONFIDENTIALITY.

HOW DO THEY

COMBINE

TO ENSURE

ADOLESCENTS

HEALTH? 
no opera frente a los propios agresores, sino frente a las autoridades competentes del Estado.

Otra disposición muy importante de este documento que no cabe silenciar, aunque no sea el tema estricto de estas reflexiones, es la que dice: «Ninguna niña puede estar sujeta a mutilaciones genitales», y remite al WMA Statement on Female Genital Mutilation.

La existencia de estas normas (que se incluyen en el denominado soft law), no ha eliminado las dificultades generadas en la aplicación de las normas positivas sobre secreto médico respecto de los niños y adolescentes.

\section{UN PROBLEMA ESPECÍFICO: LA POSICIÓN POSITIVA Y EL PROBLEMA DEL PAGO DE LOS HONORARIOS MÉDICOS}

No niego importancia a la cuestión relativa a quién toma a cargo el pago de los servicios. Cuando esos servicios los presta el Estado gratuitamente, no hay problemas.

Tampoco si el menor paga. Esto es posible, a veces, cuando se trata de una consulta, o de tratamientos o intervenciones breves. En cambio, cuando el adolescente requiere un tratamiento largo, no parece que el menor se pueda hacer cargo.

El secreto también parece debilitarse cuando los servicios son a cargo de la seguridad social y el beneficiario titular es el representante legal. La situación, en estos casos, parece limitar la autonomía.

\section{JURISPRUDENCIA QUE APOYA LA TESIS AFIRMATIVA}

Un tribunal de Bruselas dijo el 28 de marzo de 1900 que si el médico tuviese derecho de dirigirse al representante legal del paciente menor de edad que se fue a vivir al extranjero para cobrar sus honorarios, no podría hacerlo sin violar el secreto profesional, revelando al padre la naturaleza de la enfermedad que motivó el pedido de cuidados, especialmente, en el caso en que el médico fue consultado por una enfermedad llamada secreta, que evidentemente el menor deseaba ocultar a su padre ${ }^{49}$. 


\section{CONSECUENCIAS DE LA TESIS AFIRMATIVA: EL MÉDICO, INTERMEDIARIO ENTRE EL NIÑO Y LA FAMILIA}

La obligación de guardar el secreto coloca al médico en el carácter de intermediario entre el adolescente y sus representantes legales. Más aun, él debe ofrecerse para actuar como tal.

\section{EXCEPCIONES A LA OBLIGACIÓN DE GUARDAR EL SECRETO}

El derecho al secreto no es absoluto, sea el paciente adulto o adolescente; en todas las épocas, se han reconocido excepciones. Como regla, la revelación de la información médica a los integrantes de la familia sin el consentimiento del paciente, sea este plenamente capaz o un adolescente maduro, se justifica en circunstancias excepcionales, cuando la información permite a los miembros del grupo familiar evitar serias lesiones físicas o incluso la muerte.

Ver los siguientes casos:

a. La importancia de las epidemias, la observación de su carácter mortal, hizo aparecer la necesidad de declararlas para poder tomar medidas destinadas a reducir la propagación. Así, por ejemplo, en 1640, en un tratado sobre la peste, F. Ranchin, que conducía la Universidad de Montpellier, escribió: «Los médicos, cirujanos y farmacéuticos están obligados a informar al Consejo de Salud sobre el número y calidad de sus enfermos y, particularmente, la condición en la que los enfermos se encuentran; este informe sobre los enfermos debe ser diario a fin de que se puedan tomar medidas $»^{50}$. Actualmente, entre los casos de excepción que permiten revelar el secreto, se mencionan las enfermedades contagiosas. El riesgo de contagio implica la necesidad de que las personas con las cuales el paciente enfermo (plenamente capaz o adolescente) tiene contacto sean advertidas para poder protegerse a sí mismas.

b. Las enfermedades genéticas presentan algunas peculiaridades. La información genética se distingue por su carácter compartido, pues los datos no atañen solo a la persona que se somete a la prueba genética, sino también a los familiares biológicos y sus posibles descendientes, dada la condición hereditaria de las características genéticas $^{51}$. Así, por ejemplo, si a una persona se le diagnostica que es portadora de una determinada anomalía genética, puede significar que alguno de sus hermanos también lo sea. Dicho de

RESPONSABILIDAD

DE LOS PADRES,

SECRETO

PROFESIONAL Y

CONFIDENCIALIDAD

MÉDICA. ¿CÓMO

SE CONJUGAN

PARA ASEGURAR

LA SALUD DE LOS

ADOLESCENTES

PARENT'S

RESPONSIBILITY,

PROFESSIONAL

SECRECY AND

MEDICAL

CONFIDENTIALITY.

HOW DO THEY

COMBINE

TO ENSURE

ADOLESCENTS

HEALTH? 
otro modo, la información sobre la constitución genética de un individuo puede ser también información de sus familiares por lo que estos familiares pueden tener un interés significativo en acceder a esa información. La Comisión de Genética Humana de Inglaterra dijo en el año 2002: «La revelación de información genética personal y sensible en beneficio de los integrantes de la familia puede estar justificada en ciertas circunstancias, cuando el paciente no da su consentimiento para esta revelación y el beneficio de esa revelación es sustancialmente de mucho mayor peso que la demanda de confidencialidad del paciente ${ }^{52}$. En esta línea, algunos sostienen que esa información, más que pertenecer al paciente, corresponde a la familia. Sin embargo, esa titularidad conjunta, que puede afirmarse desde un punto de vista biológico, no lo es desde una perspectiva jurídica; la quiebra de la confidencialidad acabaría teniendo un efecto negativo de magnitud en la protección de la salud en general ${ }^{53}$, por lo que se trata, como en otros supuestos, de casos de excepción.

c. Para los supuestos específicos de pacientes adolescentes, maduros, o autónomos, hay un cierto acuerdo en que el secreto puede ser relevado en situaciones de excepcional riesgo o peligro, como es el caso del menor que amenaza suicidarse, o causar lesiones a otros. Pero, aun así, los jueces exigen, para relevar del secreto, que: (i) pueda identificarse el pariente o familiar a quien se alertará; (ii) hay conciencia del riesgo serio y grave; (iii) se entiende que revelando la información, serios daños pueden ser prevenidos ${ }^{54}$.

\section{UN CASO PARTICULAR: LA INTERRUPCIÓN DEL EMBARAZO SIN COMUNICACIÓN A LOS PADRES EN LOS PAÍSES EN LOS QUE LA PRÁCTICA ES LÍCITA. EL SECRETO MÉDICO FRENTE AL PEDIDO DE LA ADOLESCENTE QUE LA INTERVENCIÓN NO SE COMUNIQUE A LOS PADRES}

El informe presentado ante la Asamblea de Naciones Unidas el 3 de agosto de 2011, titulado El derecho de toda persona al disfrute del más alto nivel posible de salud física y mental, preparado por Anand Grover, Relator Especial del Consejo de Derechos Humanos, recuerda la preocupación del Comité de los Derechos del Niño por los efectos nocivos producidos por las leyes que restringen el aborto en el derecho a la salud de las 
niñas adolescentes (número 22). También refiere que algunos Estados obligan a las adolescentes a obtener el consentimiento de sus padres para adquirir determinados medios anticonceptivos; califica a estas leyes como órdenes normativos que «infringen el derecho de las niñas a tomar decisiones libres y bien fundadas en lo que respecta a su salud sexual y reproductiva», y señala que responden a «nociones discriminatorias del papel de la mujer en la familia y en la sociedad» (número 57).

Afortunadamente, también existen normas y decisiones jurisprudenciales que escapan a estos calificativos, tales como las que se mencionan a continuación, a modo de ejemplo.

a. En Alemania, después de una decisión judicial del 24 de abril de 1997, la mayoría de los autores aprueba la práctica médica según la cual no se necesita autorización parental para practicar la interrupción del embarazo si la adolescente es apta para comprender las consecuencias de sus actos. La capacidad de discernimiento se presume a los 16 años, pero el médico debe evaluar la capacidad de facto de cada menor y puede entender que una adolescente más joven tiene discernimiento. Por eso, la determinación de si la adolescente es o no madura, tiene o no competencia o autonomía, recae sobre las espaldas del médico. En definitiva, el profesional no está habilitado para informar a los parientes sin el acuerdo del interesado, siempre que este tenga discernimiento; si no lo tiene, la voluntad de los padres debe ser requerida. Si la paciente mantiene su voluntad de abortar, debe orientarla hacia un centro de planificación familiar donde, como a cualquier mujer adulta, se le dará un plazo de reflexión de tres días; si persiste en su posición, el médico practicará la interrupción del embarazo ${ }^{55}$.

b. En España, la adolescente que tiene madurez suficiente puede tomar por sí sola la decisión de interrumpir o proseguir con su embarazo. El artículo 13 de la ley del 24 de febrero de 2010 presume esa capacidad en la mujer de 16 años. Los médicos deben respetar su derecho a la confidencialidad, salvo que exista peligro para la vida de la adolescente, en cuyo caso, deben comunicarlo a los padres ${ }^{56}$.

c. En Inglaterra, las nociones de autonomía y competencia se aplicaron en el caso Axon, del año 2006. Si la joven tiene autonomía, entonces puede ir adelante con la interrupción

55 FURKEL, Françoise. «L'adolescent face à l'acte médical en République Fédérale d'Allemagne. Une autonomie grandissante malgré les silences regrettables du législateur». En FEUILLET-LIGER, Brigitte \& Ryuichi IDA. Ob. cit., p. 77.

56 SAN JULIÁN, Verónica. Ob. cit., p. 161.

RESPONSABILIDAD

DE LOS PADRES,

SECRETO

PROFESIONAL Y

CONFIDENCIALIDAD

MÉDICA. ¿CÓMO

SE CONJUGAN

PARA ASEGURAR

LA SALUD DE LOS

ADOLESCENTES

PARENT'S

RESPONSIBILITY,

PROFESSIONAL

SECRECY AND

MEDICAL

CONFIDENTIALITY.

HOW DO THEY

COMBINE

TO ENSURE

ADOLESCENTS

HEALTH? 
del embarazo, sin que se comunique a sus padres, si esa es su voluntad $^{57}$.

d. En Francia, el artículo 1111-5, según redacción impuesta por la ley 2002-303 (ley relativa a los derechos de los enfermos y a la calidad del sistema de salud) dice:

El médico puede ser dispensado de obtener el consentimiento del o de los titulares de la autoridad parental sobre las decisiones médicas a tomar cuando el tratamiento o la intervención se imponen para salvaguardar la salud de una persona menor y esta se opone expresamente a que se consulte a los titulares de la autoridad parental a fin de guardar el secreto sobre su estado de salud. Sin embargo, el médico debe, desde el primer momento, esforzarse en obtener el consentimiento del menor para esta consulta. En el caso que el menor mantenga su oposición, el médico puede hacer el tratamiento o la intervención. En este caso, el menor se hace acompañar de una persona mayor a su elección. Cuando una persona menor cuyos lazos de familia se han roto es beneficiaria, a título personal, del reintegro de las prestaciones derivadas del seguro de salud o de coberturas de maternidad previstas en la ley 99/641, solo se requiere su consentimiento.

\section{OTRO CASO ESPECÍFICO. LOS TEST PARA DETECTAR VIH}

En Alemania, un adolescente maduro, sin autorización de los padres y, consecuentemente, bajo secreto, puede solicitar se le practiquen los test de despistaje del sida y que se guarde secreto sobre su resultado ${ }^{58}$.

En la República Argentina, la Ley Nacional de Sida número 23.798, sancionada en 1990 y reglamentada en 1991, por el decreto 1244/91 dispone:

«Art. 20- Las disposiciones de la presente ley y de las normas complementarias que se establezcan, se interpretarán teniendo presente que en ningún caso pueda:

a) Afectar la dignidad de la persona;

b) Producir cualquier efecto de marginación, estigmatización, degradación o humillación; 
c) Exceder el marco de las excepciones legales taxativas al secreto médico que siempre se interpretarán en forma respectiva;

d) Incursionar en el ámbito de la privacidad de cualquier habitante de la Nación Argentina;

e) Individualizar a las personas a través de fichas, registros o almacenamiento de datos, los cuales, a tales efectos, deberán llevarse en forma codificada».

«Art. 8o- Los profesionales que detecten el virus de inmunodeficiencia humana ( $\mathrm{VIH}$ ) o posean presunción fundada de que un individuo es portador, deberán informarles sobre el carácter infecto contagioso del mismo, los medios y formas de transmitirlo y su derecho a recibir asistencia adecuada».

La ley no contiene ninguna limitación según la edad del paciente. La doctrina entiende que el médico debe hacer comprender al portador que la notificación a los integrantes de su familia será beneficiosa para todos, por lo que es frecuente la incorporación del vocablo «paciente colaborador».

\section{CONCLUSIONES PROVISORIAS}

La regla del secreto no ha sido hecha para ser respetada hasta el absurdo ${ }^{59}$. Como se ha visto, reconoce excepciones. Sin embargo, esas excepciones, como tales, deben ser aplicadas con criterio de estricta razonabilidad. Lo ideal es que adolescentes y padres marchen unidos en la defensa del cuerpo de una persona que está en pleno desarrollo. Lamentablemente, lo ideal no siempre se concreta en la práctica; de allí, la necesidad de contar con médicos preparados para resolver estos desafíos.

Como dice Mordecai Kaplán, por regla general, los hombres no se intimidan por la complejidad creciente de la vida cuando esa complejidad abre nuevos horizontes. La autonomía progresiva es una noción compleja, pero abre nuevos horizontes; de allí, la necesidad de que sea comprendida por los padres y por todos los profesionales de la salud.

RESPONSABILIDAD DE LOS PADRES,

SECRETO

PROFESIONAL Y

CONFIDENCIALIDAD

MÉDICA. ¿CÓMO

SE CONJUGAN

PARA ASEGURAR

LA SALUD DE LOS

ADOLESCENTES

PARENT'S

RESPONSIBILITY,

PROFESSIONAL

SECRECY AND

MEDICAL

CONFIDENTIALITY.

HOW DO THEY

COMBINE

TO ENSURE

ADOLESCENTS

HEALTH? 